Article

\title{
Improving the Imazapyr Degradation by Photocatalytic Ozonation: A Comparative Study with Different Oxidative Chemical Processes
}

\author{
Salma Bougarrani ${ }^{1, *}$, Zakarya Baicha ${ }^{2,3}$, Lahbib Latrach ${ }^{4}$, Mohammed El Mahi ${ }^{2}$ and \\ Francisco José Hernandez Fernandez ${ }^{5}$ \\ 1 Laboratory of Spectroscopy, Molecular Modelling, Materials, Nanomaterials, Water and Environment, \\ University Med V, Avenue Ibn Battouta, Rabat B.P. 1014, Morocco \\ 2 Environmental Materials Team, Laboratory of Spectroscopy, Molecular Modeling, Materials, Nanomaterials, \\ Water and Environment, ENSET, Mohammed V University in Rabat, Rabat E-8007, Morocco; \\ zakarya.baicha@um5s.net.ma (Z.B.); m.elmahi@um5s.net.ma (M.E.M.) \\ 3 Department of Chemical and Environmental Engineering, Regional Campus of International Excellence \\ "Campus Mare Nostrum", Campus Muralla del Mar, Technical University of Cartagena, E-30202 Cartagena, Spain \\ 4 Faculty of Sciences Semlalia, Cadi Ayyad University, Marrakech B.P. 511, Morocco; latrachlahbib@gmail.com \\ 5 Chemical Engineering Department, Campus de Espinardo, University of Murcia, E-30071 Murcia, Spain; \\ fjhernan@um.es \\ * Correspondence: salma.bougarrani@gmail.com; Tel.: +212-660-425050
}

Received: 21 September 2020; Accepted: 5 November 2020; Published: 11 November 2020

\begin{abstract}
The degradation of imazapyr $\left(\mathrm{C}_{13} \mathrm{H}_{15} \mathrm{~N}_{3} \mathrm{O}_{3}\right)$, an active element in the aqueous solution of commercial herbicide, was investigated. This study was the first to evaluate in a comprehensive manner the efficiency of advanced oxidation processes for imazapyr degradation. Results showed that Imazapyr degradation is significantly affected by operational conditions such as $\mathrm{TiO}_{2}$ concentration, ozone concentration, initial concentration of imazapyr and $\mathrm{pH}$. The kinetics of Imazapyr consumption was the first order with respect to Imazapyr concentration and zero order with respect to ozone concentration with a constant rate of $0.247 \mathrm{~min}^{-1}$ and $0.128 \mathrm{~min}^{-1}$ for photocatalytic ozonation and heterogeneous photocatalysis, while it was the first order with respect to Imazapyr and the first order with respect to ozone concentrations when only ozone was used with a constant rate of $0.053 \mathrm{~mol} \mathrm{~L}^{-1} \mathrm{~min}^{-1}$ at $\mathrm{pH}$ 7. The results revealed that more than 90 percent of the removal efficiency representing the elimination of imazapyr was held up to $7 \mu \mathrm{M}$. Further increase in the concentration of imazapyr leads to a drop in the removal efficiency, however the total imazapyr degradation was reached in $20 \mathrm{~min}$ utilizing photocatalytic ozonation for $5 \mu \mathrm{M}$ of Imazapyr in the presence of $100 \mathrm{mg} \mathrm{L}^{-1}$ of $\mathrm{TiO}_{2}, 10 \mathrm{mg} \mathrm{L}^{-1}$ of ozone at $\mathrm{pH}$ 7. Photocatalytic ozonation and heterogeneous photocatalysis utilizing $\mathrm{TiO}_{2}$ as a semiconductor process appeared possible and well suited for the treatment of organic contaminants such as imazapyr herbicides, although at certain dosages of $\mathrm{pH}$ and common time for wastewater treatment, imazapyr was not degraded with ozonation on its own. The association of two oxidation processes, ozonation and photocatalysis, has improved oxidation efficiencies for water treatment under optimal conditions, leading to the development of non-selective hydroxyl and more reactive radicals in the oxidation medium, as well as the resulting synergistic effects between photocatalysis and ozonation that react more rapidly with imazapyr herbicide.
\end{abstract}

Keywords: degradation; imazapyr herbicide; ozonation; photocatalytic ozonation; wastewater treatment 


\section{Introduction}

Increasing industrial activity has become a significant issue leading to increased contamination of air, soil and water. To face this problem, the scientific community works to discover new techniques for the purification of contaminated environment. Various treatment methods have been studied to remove recalcitrant organic contaminants in water and minimize the plausible health dangers related to these chemicals by means of its consumption in contaminated water [1,2], among which are the advanced oxidation processes (AOPs) that are assumed to have a considerable potential to remove different persistent organic pollutants [2].

Contrary to the application of traditional physical techniques such as adsorption, flocculation, coagulation, bio-filtration, sedimentation and gas stripping [3], which very frequently transfer the pollutant from water to another medium [4], typically non-destructive and post-treatments of the absorbent materials or stable wastes are required and high priced. The AOPs are focused on developing very reactive and non-selective substances such as hydroxyl radical (OH.), ozonide $\left(\mathrm{O}_{3}{ }^{-}\right)$, superoxide $\left(\mathrm{O}_{2}{ }^{-}\right)$, photo-produced electron-hole pairs with a higher oxidizing potential than standard oxidants $\left(\mathrm{O}_{2}, \mathrm{O}_{3}, \mathrm{Cl}_{2}, \mathrm{H}_{2} \mathrm{O}_{2}, \mathrm{ClO}_{2}\right.$, etc.) leading to the mineralization and decomposition of water contaminants $[5,6]$. These oxidative species have been widely investigated to eliminate pollutants or oxidize them gradually to less harmful substances from different wastewater types, however most researches are centered on single compounds, generally at concentrations higher than these observed in wastewater $[7,8]$.

Photocatalysis has proven to be an excellent process compared to others. Organic compounds oxidate at low concentrations, low temperatures and total mineralization due to oxygen usage as an oxidant [2,9]. The utilization of titanium dioxide $\left(\mathrm{TiO}_{2}\right)$ for photo-oxidation of pollutants in an aqueous solution as a catalyst is significant because of the stability of its chemical structure, physical, electrical, biocompatibility and optical properties $[10,11]$, the $\mathrm{TiO}_{2}$ photocatalytic activity depends on electron-hole recombination, surface morphology, dispersed nature, synthetic approach, and surface charge $[6,9]$. Furthermore, the usage of ozone as a strong oxidizing reagent has been applicated to wastewater treatment samples [7,11]. Besides its expensiveness of production, ozone has a significantly lower solubility and water stability and selectively reacts at acidic $\mathrm{pH}$ with organic compounds, and in certain cases does not fully mineralize such organic substances [12]. Additionally, the application of ozone alone under irradiation does not show high degradation efficiency because of slow ozone reaction with certain organic substances [13]. Such inconveniences enable the use of ozone alone to treat wastewater economically and technically inappropriate.

One alternative to improve the efficiency of mineralization is the ozone usage in the presence of a catalyst to increase the free radical hydroxyl production $[12,13]$. The photocatalytic ozonation has been investigated by several research groups globally and a synergistic effect between photocatalysis and ozonation has explained the high efficiency of this process. The photogenerated electrons may interact with molecules of ozone-producing radicals of ozonide, thus declining the ability for electron hole pairs to recombine. Lee et al. and Ebrahimi et al. reported that photocatalytic ozonation was the most effective of six different advanced oxidation processes for complete mineralization of 4-chloro-nitrobenzene [14]. These promising techniques are used to treat polluted water and wastewater to assess their capacity to eliminate contaminants, such as antibiotics and pesticides, and to evaluate the treatment effectiveness of these combinations $[15,16]$.

One of the most spread types of contaminants of waters and soils are pesticides. Imazapyr, 2-(4-methyl-5-oxo-4-propan-2-yl-1H-imidazol-2-yl) pyridine-3-carboxylic acid is a non-selective herbicide of the imadazolinone family, it is characterized by a high soil mobility and a lifetime between 3 weeks and 49 months [16]. Therefore, groundwater pollution is possibly suspected [16,17]. Essays to remove imazapyr in potable water by ozone treatment have proven ineffective as $50 \%$ of the primary substances reside in water after the process. Previously, photocatalytic oxidation of imazapyr was investigated employing commercial $\mathrm{TiO}_{2}$ and newly synthesized mesoporous $\mathrm{TiO}_{2}$ materials $[18,19]$. Nevertheless, for better comprehension of the impact of oxidative alternatives on 
evaluating this herbicide, further studies are still needed. Moreover, photocatalytic ozonation has been reported to be more effective than single ozonation in the degradation of standard by-products (such as oxalic acid), and highly efficient compared to photocatalysis in removing the source of micro pollutants defined in wastewater $[12,16]$. Photocatalytic ozonation is the most appropriate method for the treatment of streams polluted by this form of contaminants, though its capability to fully degrade most stable complexes has been confirmed [17,19].

However, the development of this method for imazapyr herbicide degradation needs more studies to understand all the variables which affect the process performance. For instance, a couple of reviews were published within the last years about the application of photocatalytic ozonation for the removal of pharmaceuticals and some pesticides effluents; many of the researches already carried out have been based on the direct photolytic and photocatalytic decomposition of the imazapyr but not much is learned about the ability for removing imazapyr by photocatalytic ozonation a non-biodegradable pesticide from wastewater [14,20]. Currently, the literature is sparse; in January 2019, publications on "photocatalytic ozonation" in Scopus were below 300 scientific papers, compared with more than 35,500 for "photocatalysis" and 12,000 for "ozonolysis or ozonation" [21].

Based on this data, the purpose of this study was to conduct a comprehensive assessment of the potential of photocatalytic ozonation to treat imazapyr from polluted water and compare this technology with many different AOPs: ozonation, heterogeneous photocatalysis process (applying $\mathrm{TiO}_{2}$ Degussa P25 as a semiconductor), and photolysis to evaluate the impact of different experimental parameters on the effect of the mass of $\mathrm{TiO}_{2}$, the effect of initial herbicide concentration and the $\mathrm{pH}$ influence on the decomposition of imazapyr in aqueous media.

\section{Materials and Methods}

\subsection{Material}

Imazapyr herbicide (95 percent), obtained from the American Cyanamid Company and utilized without further purification, is shown in Figure $1 . \mathrm{TiO}_{2}$ (Degussa P-25), which is available commercially, was obtained from Degussa Chemical. The rest of chemicals used in the experiments were obtained from Riedel-de Hahn AG and were used without any other cleansing. Entire solutions were prepared utilizing Milli-Q water obtained from Milli-Q apparatus at room temperature, (Millipore, Bedford). Analytical value organic solvents have been used for high-performance liquid chromatography (HPLC).

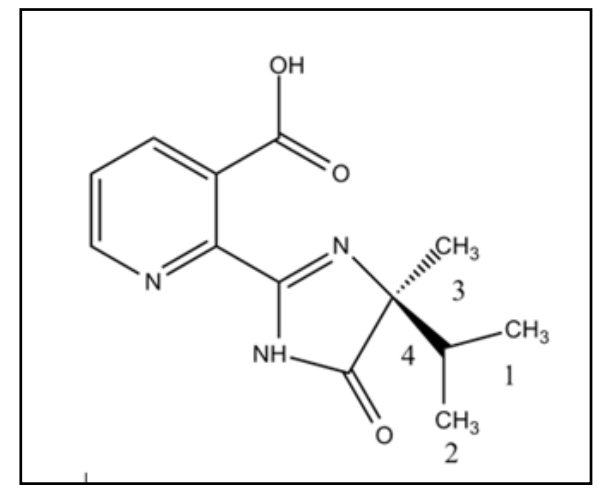

Figure 1. Chemical structure of imazapyr herbicide.

\subsection{Methods}

The imazapyr degradation proceeded with usage of a Hitachi HPLC system equipped with a UV detector. The input volume was $50 \mu \mathrm{L}$, the debit was $0.5 \mathrm{~mL} \mathrm{~min}^{-1}$ and the eluent was composed from acetonitrile (ACN) and a water $\mathrm{pH} 3.4$ (formic acid) mixture. The used column was Phenomenex $\mathrm{C} 18(25 \mathrm{~cm} \times 4.6 \mathrm{~mm}, 5 \mu \mathrm{m})$. With no further preparation, samples from reaction solutions were inserted into the chromatograph. According to Ikehata et al. [20], the concentration of the aqueous 
ozone was determined by the Spectrometric method indigo trisulfonate. Shimadzu UV-160A UV-Vis Spectrophotometer was monitored at $600 \mathrm{~nm}$ for the absorption analysis of the indigo. The $\mathrm{pH}$ was adjusted using hydrochloric acid solution to reach the desired acidic $\mathrm{pH}$ and sodium hydroxide solution to reach the alkaline $\mathrm{pH}$, and three solutions were prepared: solution $\mathrm{pH} 3$, solution $\mathrm{pH}$, solution $\mathrm{pH} 10$.

\subsection{Photocatalytic Experiments}

Titanium dioxide (Degussa P-25) was utilized without pre-treatment. In a standard reaction, $100 \mathrm{mg} \mathrm{L}^{-1}$ of $\mathrm{TiO}_{2}$ were added for each $500 \mathrm{~mL}$ of $5 \mu \mathrm{M}$ of imazapyr solution in a double walled cylindrical photoreactor (shown in Figure 2). For catalyst suspension, the solution was then subjected to ultrasonic treatment for $2 \mathrm{~min}$. Immediately afterwards the spinning began, and it was kept in the dark for over $1 \mathrm{~h}$ to guarantee the balance of adsorption between the solution and the particles of the catalyst.

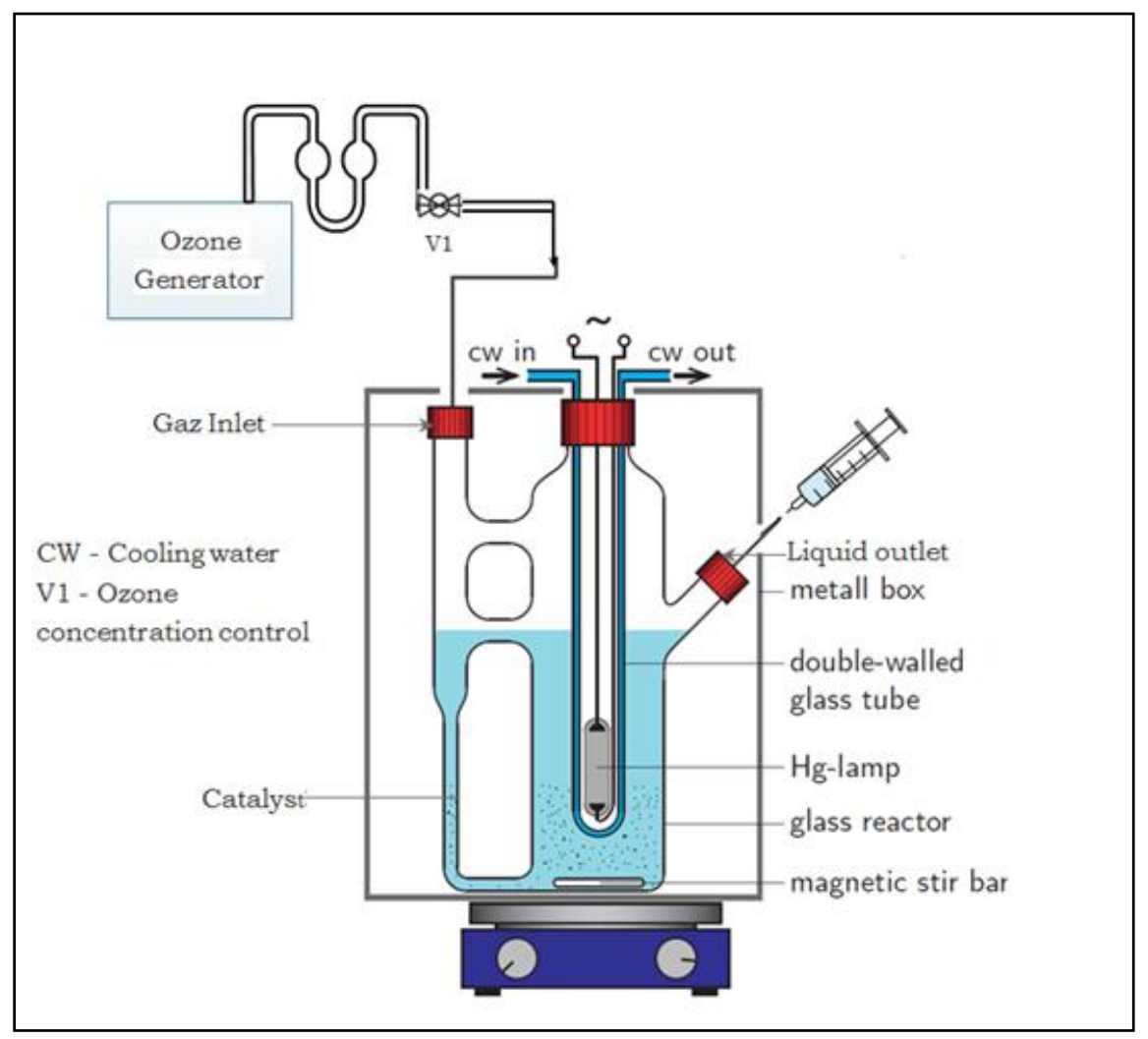

Figure 2. Scheme of the reactor used for imazapyr degradation.

The irradiation experiments were performed under light produced by a $150 \mathrm{~W}$ medium-pressure mercury lamp in a Duran cell (I > $300 \mathrm{~nm}$ ) inside the reactor. Furthermore, a cooling water system was developed to avoid overheating of the solution and the lamp. Samples were taken every $5 \mathrm{~min}$ using a $2 \mathrm{~mL}$ syringe. Samples were collected every $10 \mathrm{~min}$ and were filtered twice to eliminate all the catalyst traces.

\subsection{Photolysis Experiment}

The same experimental procedure was employed as explained in the earlier section, apart from $\mathrm{TiO}_{2}$ suspension being applied. 


\subsubsection{Ozonation Experiment}

The ozone treatment was carried out using a generator with a capacity of production of about $200 \mathrm{mg} \mathrm{h}^{-1}$ of ozone gas produced from air and injected into the sample. The input power was AC220 V/50 Hz and the pump output was 2-3 $\mathrm{L} \mathrm{min}^{-1}$. The quantity of ozone was estimated using the volumetric procedure that trapped it in the KI solution, and used regular thiosulfate solution with starch as an identifier of the liberated iodine. Ozone concentrations and flow rates were calibrated and highly reproducible. All of the experiments were realized in a semi-batch reactor with continuous ozone spray. Consequently, steady-state concentration of ozone was maintained. Parameters were checked before and after each experiment in duplicate runs. The same procedure was adopted for experimental control in the dark.

\subsubsection{Photocatalytic Ozonation Experiment}

The experiments on imazapyr degradation were performed in a simple photocatalytic ozonation reactor, as shown in Figure 2, with the same procedures reported below but with combining photocatalysis and ozonation.

\section{Results and Discussion}

\subsection{Photocatalytic Degradation of Imazapyr}

In order to compare the efficiency of photolysis (UV), heterogeneous photocatalysis $\left(\mathrm{TiO}_{2} / \mathrm{UV}\right)$, ozonation $\left(\mathrm{O}_{3} / \mathrm{UV}\right)$ and photocatalytic ozonation $\left(\mathrm{O}_{3} / \mathrm{TiO}_{2} / \mathrm{UV}\right)$, experiments were performed by the usage of the initial concentration of pesticide and the same amount of $\mathrm{TiO}_{2}$ at $\mathrm{pH} 7$ (Figure 3). Imazapyr was initially the unique organic compound existing in the solutions employed in this investigation. The HPLC imazapyr degradation chromatograms after $10 \mathrm{~min}$ of irradiation with various oxidative chemical processes are inserted into Figure 3.

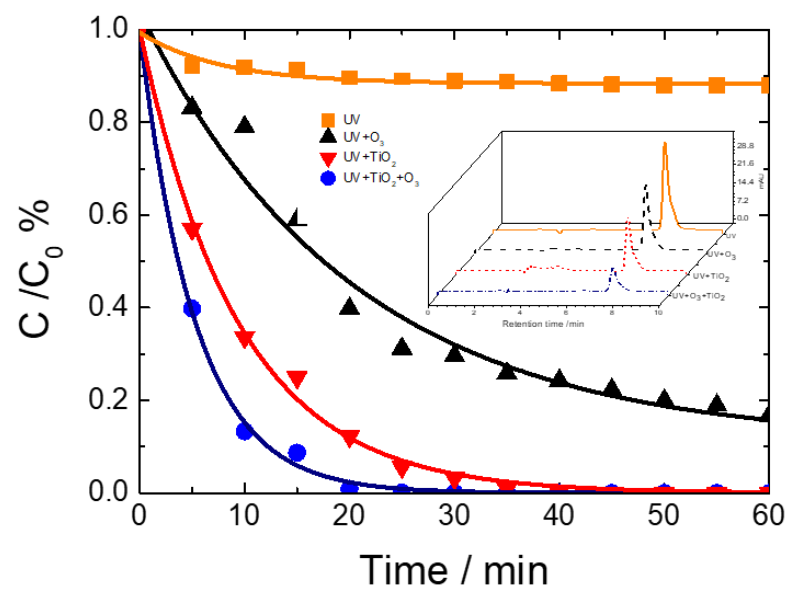

Figure 3. Imazapyr degradation as a function of time by several oxidative chemical processes: photolysis, ozonation, photocatalysis and photocatalytic ozonation. $\mathrm{C}_{(\text {Imazapyr) }}=5 \mu \mathrm{M}$; stirring speed $=1000 \mathrm{~min}^{-1}, \mathrm{TiO}_{2}=50 \mathrm{mg}, \mathrm{pH} 7$.

The suggested mechanism of photocatalytic efficiency of $\mathrm{Ga}_{2} \mathrm{O}_{3}-\mathrm{TiO}_{2}$ nanocomposites and $\mathrm{TiO}_{2}-\mathrm{Ca} x \mathrm{MnO} y$ hetero-nanostructures on Imazapyr photo-degradation under ultraviolet radiation were reported by Ismail et al. [22] and Bougarrani et al. [16], as illustrated in Figure 4. As expected, photocatalytic ozonation showed the highest degradation efficiency for imazapyr herbicide since by forming $\mathrm{OH}$ radicals, positive holes will oxidize the adsorbed organic molecules on the surface principally associated to non-selective hydroxyl radicals formation and more reactive in the oxidation environment, and also, the resulting synergistic effects between photocatalysts and ozone, which react more rapidly with imazapyr herbicide. The photogenerated electrons can produce 
radicals, particularly hydroperoxide $\mathrm{HO}_{2}{ }^{-}$and superoxide $\mathrm{O}_{2}{ }^{-}$, and react with the molecules of ozone allowing the generation of ozonide radicals and reducing the eventual electron hole pairs recombination $[23,24]$. Similar results for dibutyl phthalate, chlortetracycline and carbaryl mineralization were reported, comparing photocatalytic ozonation with other advanced technologies of oxidation $[25,26]$. Furthermore, heterogeneous photocatalysis shows higher degradation of imazapyr compared to the ozonation process; complete degradation was accomplished after $40 \mathrm{~min}$ of illumination. On the other hand, less than $5 \%$ of imazapyr degradation was found when the direct photolysis was used. Studies show that generally direct photolysis is not an alternative because of its low effectiveness for the most of pesticides [27].

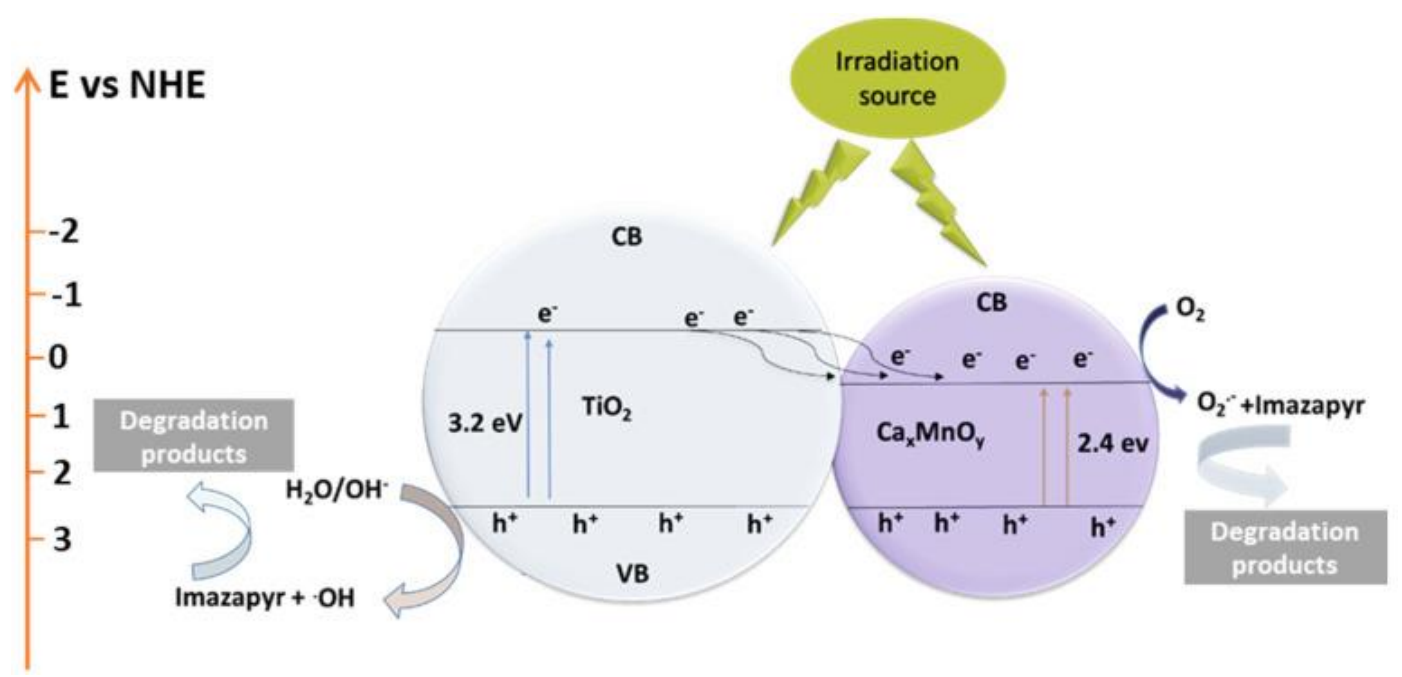

Figure 4. Band scheme for the enhancement in the photocatalytic activity of $\mathrm{TiO}_{2}$ by $\mathrm{Ca} x \mathrm{MnO} y$ modification the photodegradation of Imazapyr [16].

\subsection{Effects of Parameters on the Degradation of Imazapyr}

\subsubsection{Effect of $\mathrm{TiO}_{2}$ Dosage on Imazapyr Degradation}

The influence of catalyst quantity on imazapyr degradation was studied in the range 50 to $400 \mathrm{mg} \mathrm{L}^{-1}$ under $\mathrm{pH} 7$ and the results are shown in Figure 5. As shown, imazapyr degradation increased to $96.00 \%$ by increasing catalyst concentration to $100 \mathrm{mg} \mathrm{L}^{-1}$, beyond which the effect is less pronounced. Thus, $100 \mathrm{mg} \mathrm{L}^{-1}$ of $\mathrm{TiO}_{2}-\mathrm{P} 25$ could be considered as the optimal concentration, and this amount fits well with proclaimed results by other studies [7,28]. This increase can be related to growing active locations by supplying more $\mathrm{TiO}_{2}$ particles, which serves as a semiconductor in the process of photocatalysis. Thus, the development of reactive hydroxyl radicals and electron-hole pairs on the semiconductor surface was raised, which improved the imazapyr oxidation into other intermediates. The results are in accordance with our last publications $[7,29]$ which proved that increased molecular weight and pollutant complexity may induce intermediates generation, which can be adsorbed on the catalyst surface. 


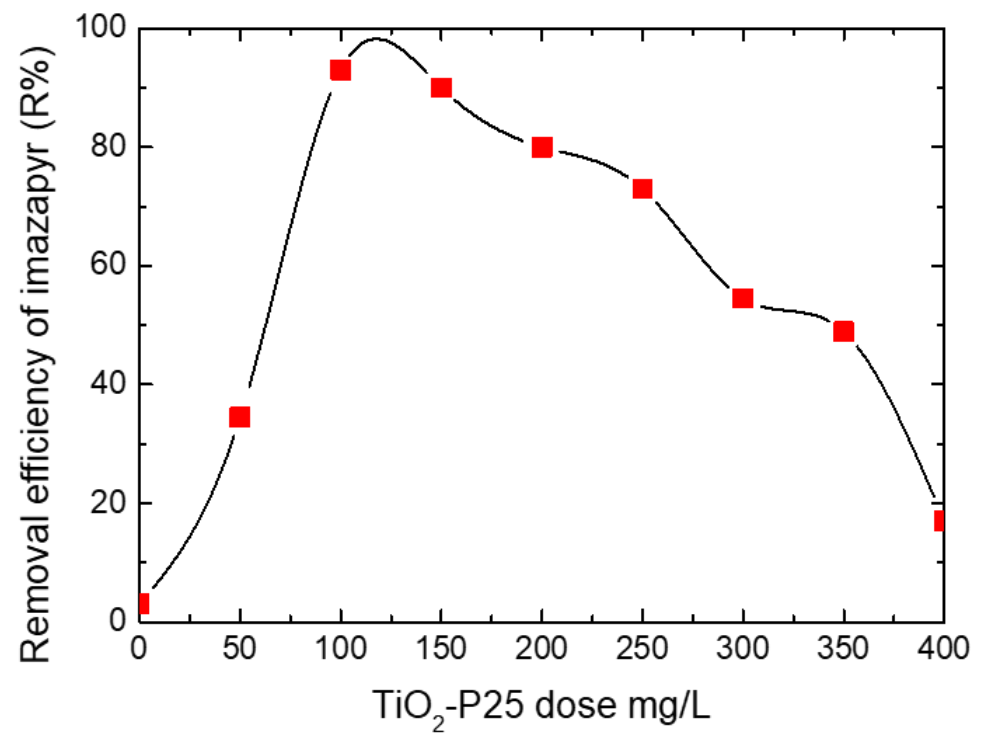

Figure 5. Removal efficiency of imazapyr under variation of $\mathrm{TiO}_{2}$ concentration. $\mathrm{C}_{(\mathrm{Imazapyr})}=5 \mu \mathrm{M}$, stirring speed $=1000 \mathrm{~min}^{-1}$, aqueous suspension Milli-Q water.

\subsubsection{Effect of Initial Concentration of Ozone}

The influence of ozone concentration on imazapyr degradation was studied in the range of 5 to $50 \mathrm{mg} \mathrm{L}^{-1}$ under $\mathrm{pH}$. The dosage of the $\mathrm{TiO}_{2}$ catalyst was held constant at $100 \mathrm{mg} \mathrm{L}^{-1}$ with keeping the same conditions of the above experiments. The results presented in Figure 6 shows that an increase in the ozone concentration increases imazapyr degradation efficiency due to the high oxidant/contaminant ratio [5,29]. Thus, a removal efficiency of $97.3 \%$ was obtained for ozone concentration of $10 \mathrm{mg} / \mathrm{L}$. This result indicates that an increase in the ozone concentration led to a further ozone mass transfer improving the removal efficiency of imazapyr [29]. This is because the ozone is more electrophilic than the oxygen towards electrons generated on the titanium dioxide surface $[29,30]$.

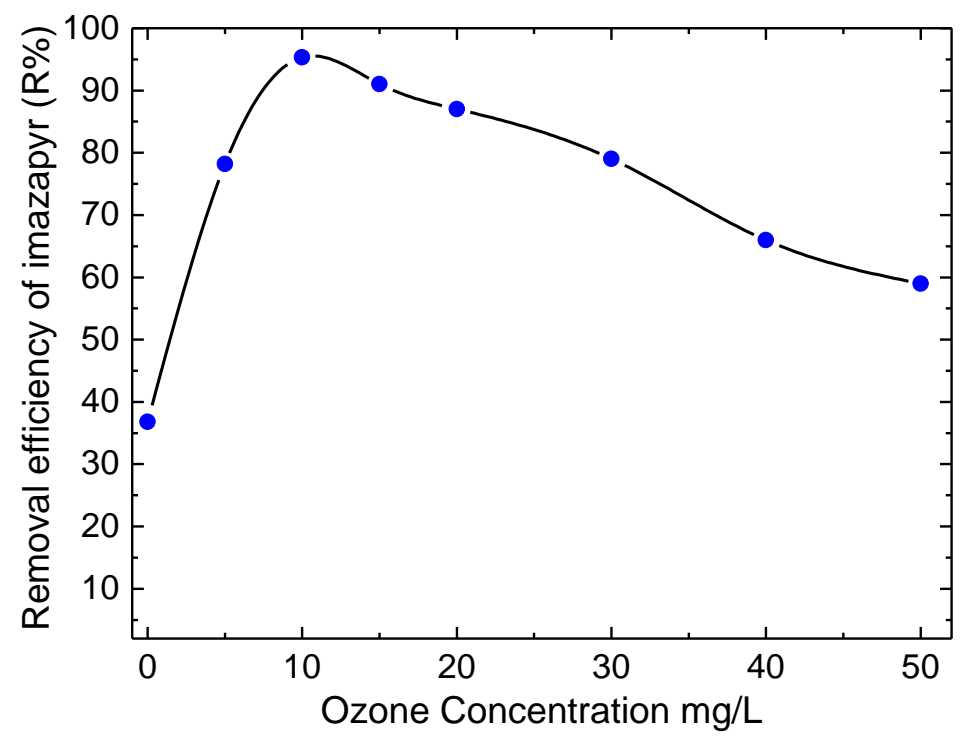

Figure 6. Removal efficiency of imazapyr under variation of ozone concentration. $\mathrm{C}_{(\mathrm{Imazapyr})}=5 \mu \mathrm{M}$; $\mathrm{C}_{\mathrm{TiO} 2}=100 \mathrm{mg} \mathrm{L}^{-1}$; stirring speed $=1000 \mathrm{~min}^{-1}$, aqueous suspension Milli-Q water. 


\subsubsection{Effect of Initial Concentration of Herbicide on Imazapyr Degradation}

The concentration of pollutants in water is a crucial parameter to determinate the oxidation effectiveness. The initial concentration effect of herbicide was studied for six imazapyr concentrations by photocatalysis, ozonation and photocatalytic ozonation (Figure 7). The initial concentrations of herbicide were $1 \mu \mathrm{M}, 3 \mu \mathrm{M}, 5 \mu \mathrm{M}, 7 \mu \mathrm{M}, 9 \mu \mathrm{M}$ and $15 \mu \mathrm{M}\left(0.26 \mathrm{mg} \mathrm{L}^{-1}, 0.79 \mathrm{mg} \mathrm{L}^{-1}, 1.31 \mathrm{mg} \mathrm{L}^{-1}\right.$, $1.83 \mathrm{mg} \mathrm{L}^{-1}, 2.36 \mathrm{mg} \mathrm{L}^{-1}, 3.90 \mathrm{mg} \mathrm{L}^{-1}$, respectively). The dosages of the catalyst and the ozone were held constant at $100 \mathrm{mg} \mathrm{L}^{-1}$ and $10 \mathrm{mg} \mathrm{L}^{-1}$, respectively, for this series of experiments. Under dark conditions the illumination time was set at $10 \mathrm{~min}$ for each sample after the adsorption stage.

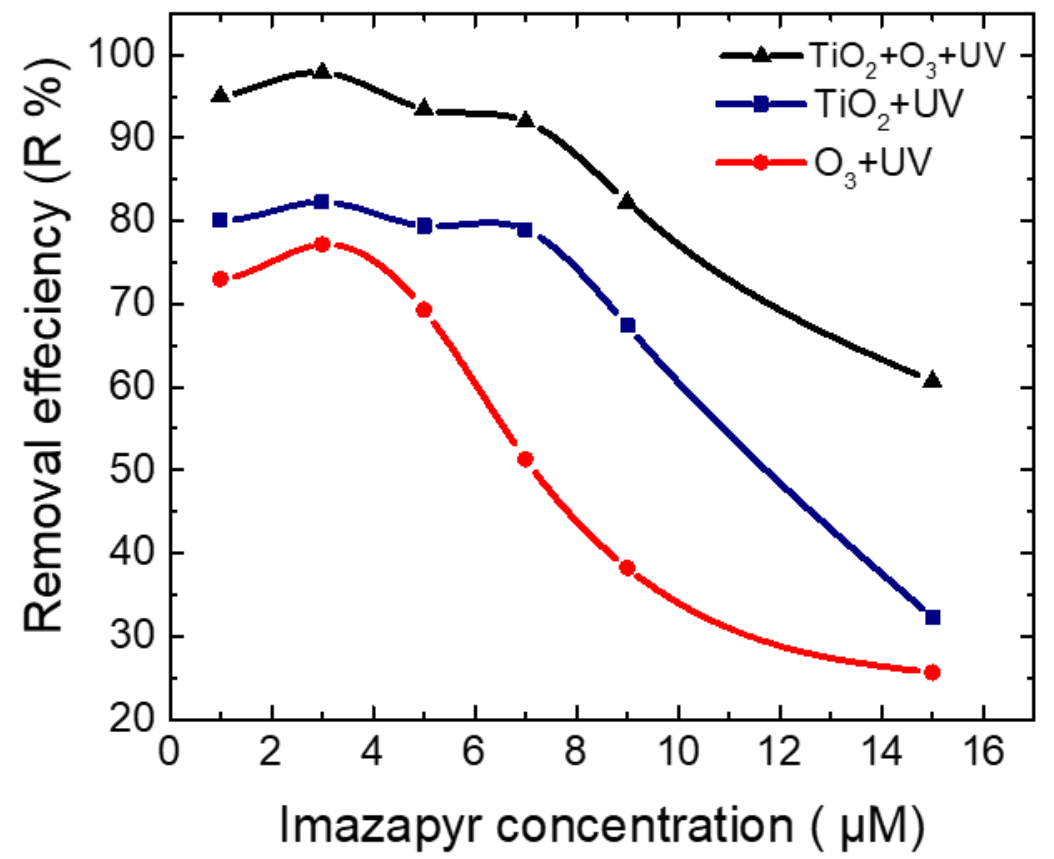

Figure 7. Removal efficiency as a function of imazapyr concentration, $\mathrm{m} \mathrm{TiO}_{2}=50 \mathrm{mg}$; stirring speed $=1000 \mathrm{~min}^{-1}$, aqueous suspension Milli-Q water.

Obtained results showed that removal efficiency represented the disappearance of the imazapyr drop after a certain limit, with an increase in the initial concentration of imazapyr. As shown in Figure 5, high removal efficiency was maintained until $7 \mu \mathrm{M}$ of imazapyr concentration for photocatalytic ozonation and photocatalysis, respectively, but gradually decreases with increasing imazapyr concentration. However, for ozone treatment, the removal efficiency declined considerably when imazapyr concentration was up to $3 \mu \mathrm{M}$. One probable reason lies in the fact that as the concentration of imazapyr raises, extra organic compounds may be deposited on the $\mathrm{TiO}_{2}$ surface, while less photons are able to attain the surface of the catalyst and the possibility of interaction between the molecules of imazapyr and oxidizing species also diminishes, leading to lower percentage degradation. Moreover, other researchers have reported that increasing the initial concentration of contaminants in water induces a higher percentage of degradation [31] as a result of greater availability of contaminants for oxidative reactions with active oxidizing species $[29,30]$. This behavior was observed as the imazapyr concentration increasing from 1 to $3 \mu \mathrm{M}$, thus, removal efficiency increased with approximatively $5 \%$ for all treatment processes.

\subsubsection{Influence of $\mathrm{pH}$ on Imazapyr Degradation}

In the aim of evaluating the effect of $\mathrm{pH}$ on imazapyr degradation by various oxidative chemical processes (photolysis, photocatalysis, ozonation and photocatalytic ozonation), experiments were carried out at acidic pH 3.00, neutral pH 7.00 and basic pH 10.00. Concentrations of imazapyr have 
been shown to decrease with irradiation time in all experimental tests. The photoactivity profile was designed based on the exponential decay of imazapyr concentration, supposing a first-order reaction.

$$
C=C_{0} \exp (-k \cdot t)
$$

In which $C$ is the imazapyr concentration at time $t, C_{0}$ is the initial concentration, and $k$ is the observed rate constant.

Several researchers have stated that a modified Langmuir-Hinshelwood model can explain the kinetic behavior of the photocatalytic reaction [21,32]. Comparison of imazapyr herbicide degradation at different initial $\mathrm{pH}$ solution values using photocatalysis is shown in Figure 8A. At pH 3.00, kinetics of Imazapyr consumption was the first order with respect to Imazapyr concentration and zero order with respect to ozone concentration with a rate constant of $0.188 \mathrm{~min}^{-1}$. Therefore, the photocatalytic activity dropped significantly for $\mathrm{pH} 7.00$ and 10.00, the constant rates achieved $0.128 \mathrm{~min}^{-1}, 0.095 \mathrm{~min}^{-1}$, respectively. The $\mathrm{pH}$ effect on imazapyr degradation supported by the $\mathrm{TiO}_{2} \mathrm{P}-25$ is affected by the equilibrium of acid-base dominating the metal oxides surface in water. It is widely acknowledged that the $\mathrm{TiO}_{2}$ surface is charged positively at $\mathrm{pH}$ levels under the zero-charge point $(\mathrm{pHpzc})$ of the $\mathrm{TiO}_{2}$ sample, neutral at the $\mathrm{pHpzc}$, and charged negatively at $\mathrm{pH}$ levels beyond the $\mathrm{pHpzc}$. Furthermore, the pHpzc of the photocatalyst $\mathrm{TiO}_{2} \mathrm{P}-25$ is described as between 6.30 and 6.60 . Imazapyr has $5 \mathrm{pKa}$ 's, according to the development of five varied ionic species, based on the $\mathrm{pH}$ of the solution various sorts of interactions between the charged $\mathrm{TiO}_{2}$ surface and the probe molecule are expected (Figure 9).
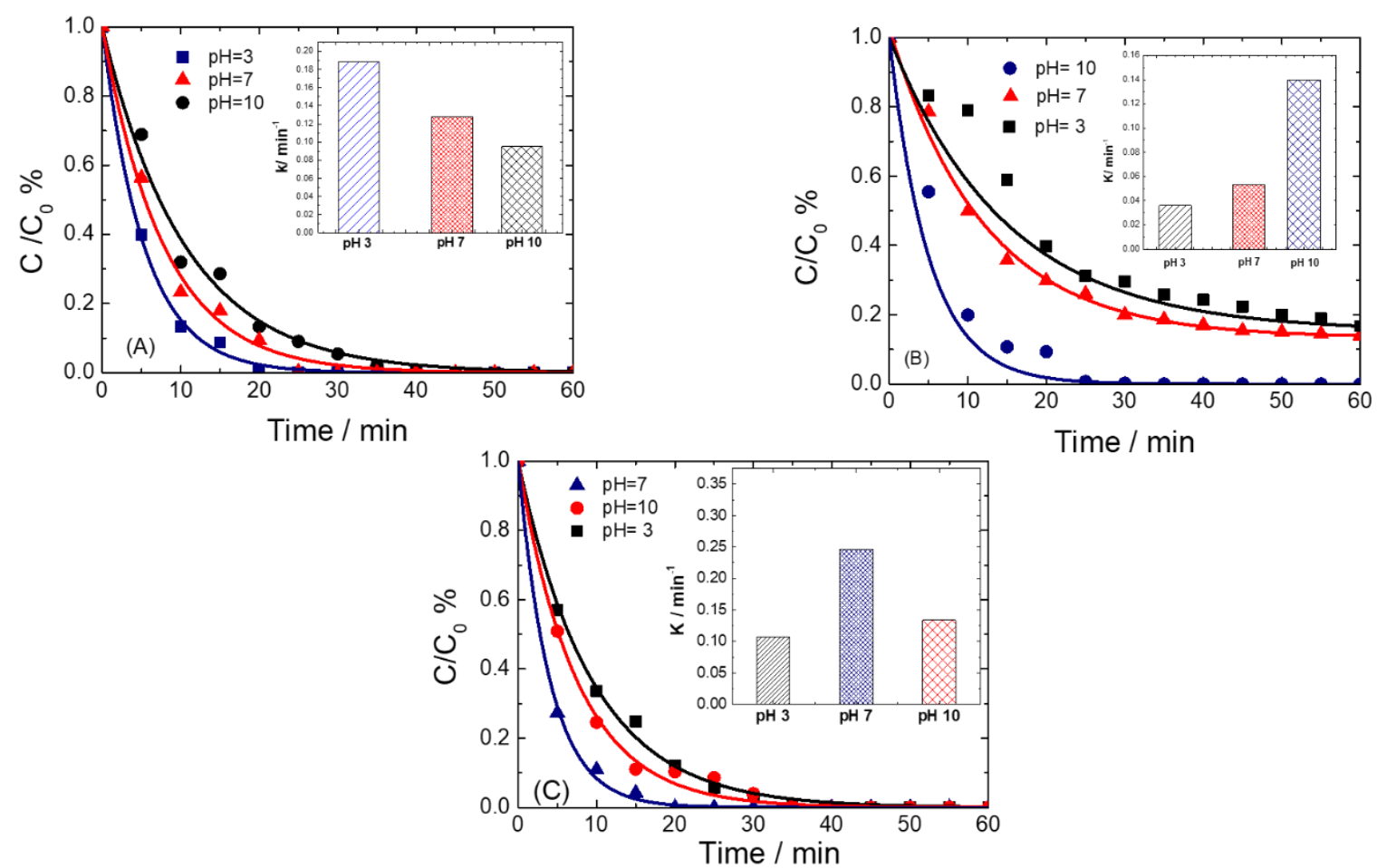

Figure 8. Imazapyr degradation as a function of time for different $\mathrm{pH}$ by photocatalysis (A), ozonation (B), photocatalytic ozonation (C) $\left.\mathrm{C}_{(\text {Imazapyr) }}=5 \mu \mathrm{M}\right)$; stirring speed $=1000 \mathrm{~min}^{-1}$, $\mathrm{m} \mathrm{TiO}_{2}=50 \mathrm{mg}$ ). aqueous suspension Milli-Q water. 


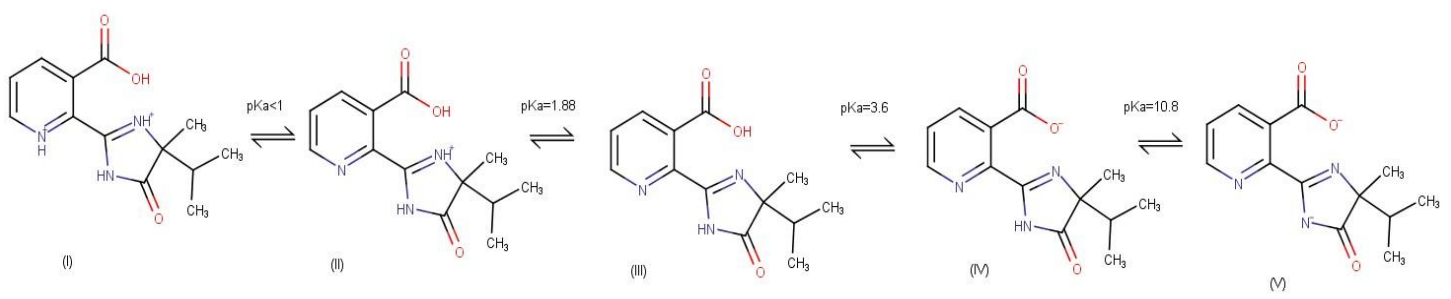

Figure 9. Imazapyr different forms as a function of the $\mathrm{pH}$.

At $\mathrm{pH}$ between 1.90 and 3.60 for the imazapyr neutral form (III in Figure 9), and at $3.60<\mathrm{pH}<\mathrm{pHpzc}\left(\mathrm{TiO}_{2}\right)$, the imazapyr charged negatively (IV) will be the principle species interacting with the positively charged $\mathrm{TiO}_{2}$ surface $\mathrm{TiOH}^{2+}$. The high rate constant for imazapyr degradation for $\mathrm{pH}$ below 6.40 may be described by the high electrostatic attraction between positive charge of $\mathrm{TiO}_{2}$ and negative charge of imazapyr. On the contrary, at $\mathrm{pHpzc}\left(\mathrm{TiO}_{2}\right)<\mathrm{pH}<10.80$ the imazapyr molecule negatively charged (IV) is interacting with a negatively charged $\mathrm{TiO}_{2}$ surface, which could slow down the interactions between $\mathrm{TiO}_{2}$ catalyst and imazapyr and therefore decrease the reaction rate of imazapyr degradation.

The kinetics of Imazapyr consumption by ozone only are found to be second order, while the first order with respect to Imazapyr and the first order with respect to ozone concentrations for $\mathrm{pH} 3.00$ and $\mathrm{pH} 7.00$, and first order with respect to Imazapyr concentration and zero order with respect to ozone concentration for $\mathrm{pH} 10.00$ (Figure 8B). In acidic and neutral solutions with $\mathrm{pH} 3.00$ and 7.00, the total ozone reaction with organic components is second order, first order with regard to every reactant $(R 2=0.972 \& R 2=0.974)$, respectively. Hence, the declining rate equation of imazapyr can be expressed as follows:

$$
\frac{d[\text { imazapyr }]}{d t}=k\left[\mathrm{O}_{3}\right][\text { imazapyr }]
$$

The overall rate constant increased significantly from $0.036 \mathrm{~mol} \mathrm{~L}^{-1} \mathrm{~min}^{-1}$ to $0.053 \mathrm{~mol} \mathrm{~L}^{-1} \mathrm{~min}^{-1}$ for $\mathrm{pH} 3.00$ and $\mathrm{pH} 7.00$, respectively. The results suggest that the reactions are predominated by direct oxidation of imazapyr with ozone molecules. At an acid $\mathrm{pH}$, the molecule of ozone is the principal reactant species with a very low reactivity to hydroxyl radical, so the imazapyr degradation is very low. When the solution is getting basic, the percentage of ozone photocatalyzed degradation against secondary oxidants, in particular hydroxyl radicals, increases. Although the augmentation in $\mathrm{pH}$ promotes the concentration of hydroxyl radical, the $\mathrm{pH}$ impact on the reactivity of the substrate is very essential for an effective transformation. For alkaline solutions with $\mathrm{pH}$ value 10, the hydroxyl radical reactions seem predominated over ozonation of imazapyr. However, the imazapyr declining rate equation can be expressed as follows:

$$
\frac{d[\text { imazapyr }]}{d t}=k[\text { imazapyr }]
$$

The results obtained indicate a substantial improvement in process efficiency and the highest conversion was registered at $\mathrm{pH} 10.00$ with a constant first-order rate $0.140 \mathrm{~min}^{-1}\left(\mathrm{R}^{2}=0.993\right)$. In a literature review on the kinetics of the reaction of ozone with organic compounds, the most common observation is the recorded disagreement between different studies regarding the decomposition order $[7,14,20]$. Furthermore, it is generally agreed that pesticide degradation may be described by a first-order reaction for an alkaline solution and second order for acidic ones [17].

Studying the $\mathrm{pH}$ impact on the process of photocatalytic ozonation would clarify the mechanism of degradation and would help to achieve an important degree of removal. On the basis of the exponential decay of imazapyr concentration, photocatalytic ozonation profile degradation was also fitted on the assumption of a first-order reaction model (Figure 8C). Results similar to those have been published by Ebrahimi et al. [17], by Bamba et al. [12] and Sanchez et al. [26]. These researchers have reported first-order reaction kinetics by photocatalytic ozonation for the mineralization and degradation of 
chlorinated pesticides and insecticides and other different water contaminants. The removal rate of Imazapyr reached a maximum at $\mathrm{pH} 7.00$ with $0.247 \mathrm{~min}^{-1}$ as a first-order rate constant. Therefore, for $\mathrm{pH} 3.00$ and 10.00, the photocatalytic activity dropped noticeably. The constant rates at $\mathrm{pH} 3.00$ and $\mathrm{pH} 10.00$ achieved $0.107 \mathrm{~min}^{-1}, 0.134 \mathrm{~min}^{-1}$ respectively.

Results of the studies are shown in Table 1; optimum conditions for imazapyr degradation are obtained with photocatalytic ozonation at neutral $\mathrm{pH}$ 7.00. The combination of two different oxidation methods, photocatalysis and ozonation, for water treatment under optimal conditions have improved oxidation efficiencies (synergy) relative to the total of oxidation efficiencies for these two oxidation methods separately. Several researches have studied the synergistic impacts of photocatalytic ozonation on the removal and the degradation of various matters from aqueous solutions, and the effects are in regard to the mineralization and/or degradation efficiencies or oxidation constant rates of model water pollutants. Besides the synergistic impacts which took place during photocatalytic ozonation in comparison with simple photocatalysis in presence of oxygen, the photocatalytic ozonation efficiency is mainly due to the formation in the oxidation medium of further reactive and non-selective hydroxyl radicals that interact with practically the entire organic molecules at a rate of $10^{6}-10^{9} \mathrm{M}^{-1} \mathrm{~s}^{-1}$. Sanchez et al. [26] and Lee et al. [14] correspondingly described comparable results for the degradation of dibutylphthalate and aniline, respectively. The results were in accordance with Atitar et al. [33], who demonstrated that the imazapyr adsorption to the $\mathrm{TiO}_{2}$ molecule is $\mathrm{pH}$ dependent and takes place over electrostatic interactions and chemical bonding among the charged $\mathrm{TiO}_{2}$ surface and the probe molecule. The same study found that the imazapyr adsorption onto the $\mathrm{TiO}_{2}$ surface is favorized at $\mathrm{pH}$ rates under the zero-charge point of $\mathrm{TiO}_{2}$.

Table 1. Imazapyr degradation rate constant for photocatalytic ozonation, photocatalysis $\left(\mathrm{TiO}_{2}\right)$ and ozone.

\begin{tabular}{ccccccc}
\hline \multirow{2}{*}{$\mathbf{p H}$} & \multicolumn{2}{c}{ Photocatalytic Ozonation } & \multicolumn{2}{c}{ Photocatalysis $\left(\mathrm{TiO}_{\mathbf{2}}\right)$} & \multicolumn{2}{c}{ Ozone } \\
\cline { 2 - 7 } & Rate Constant K & $\mathbf{R}^{\mathbf{2}}$ & Rate Constant K & $\mathbf{R}^{\mathbf{2}}$ & Rate Constant K & $\mathbf{R}^{\mathbf{2}}$ \\
\hline 3 & $0.107\left(\mathrm{~min}^{-1}\right)$ & 0.997 & $0.188\left(\mathrm{~min}^{-1}\right)$ & 0.998 & $0.036\left(\mathrm{~mol} \mathrm{~L}^{-1} \mathrm{~min}^{-1}\right)$ & 0.973 \\
7 & $0.247\left(\mathrm{~min}^{-1}\right)$ & 0.997 & $0.128\left(\mathrm{~min}^{-1}\right)$ & 0.989 & $0.053\left(\mathrm{~mol} \mathrm{~L}^{-1} \mathrm{~min}^{-1}\right)$ & 0.975 \\
10 & $0.134\left(\mathrm{~min}^{-1}\right)$ & 0.995 & $0.095\left(\mathrm{~min}^{-1}\right)$ & 0.994 & $0.140\left(\mathrm{~min}^{-1}\right)$ & 0.994 \\
\hline
\end{tabular}

\subsubsection{Recyclability of Catalyst $\mathrm{TiO}_{2}$}

The stability and reusability of the $\mathrm{TiO}_{2}$ photocatalyst was checked by using a $\mathrm{TiO}_{2}$ catalyst for three consecutive cycles, as shown in Figure 10 and in the third cycle, the percentage of degradation was found to be $95.2 \%$ for photocatalytic ozonation and only $80.2 \%$ for photocatalytic experiments due to the loss of some catalyst during washing and filtration. These initial results are encouraging to indicate the reusability of the $\mathrm{TiO}_{2}$ photocatalyst to some extent. 


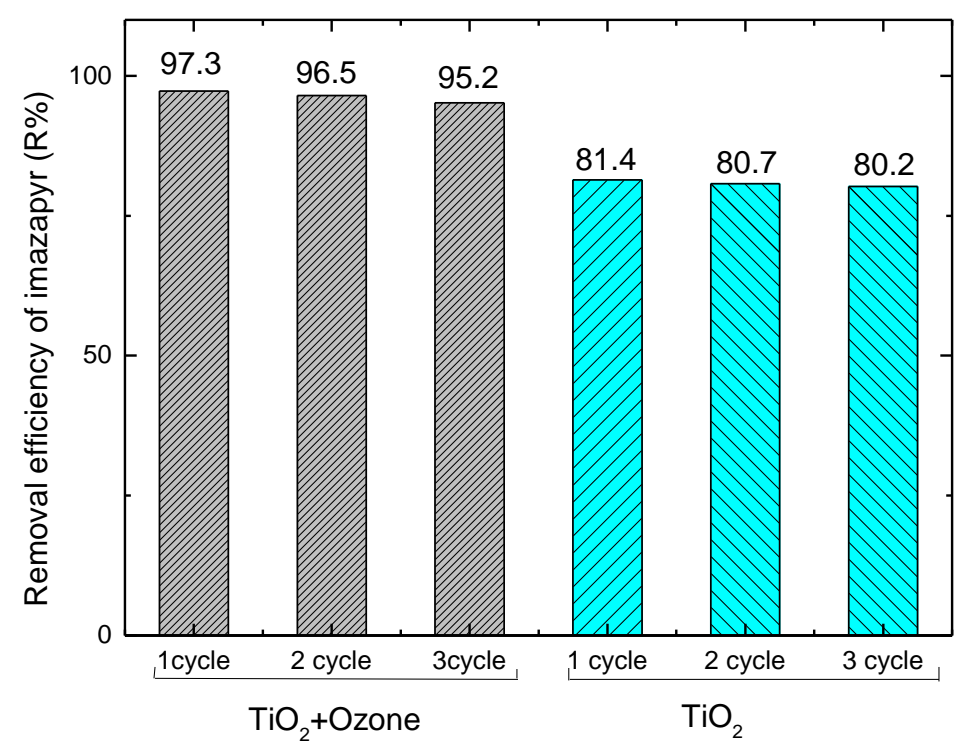

Figure 10. Catalytic recycling $\mathrm{Of}_{\mathrm{TiO}}$ (at the presence of ozone \& without) in Imazapyr degradation, stirring speed $=1000 \mathrm{~min}^{-1}, \mathrm{~m} \mathrm{TiO}_{2}=50 \mathrm{mg}$ ). Aqueous suspension Milli-Q water.

\section{Conclusions}

A comparison of results of three processes under review indicate that photocatalytic ozonation and heterogeneous photocatalysis are well fitted for organic contaminants treatment like imazapyr herbicides. Photocatalytic ozonation proved to be effective in total degradation of imazapyr under $\mathrm{pH}$ 7.00. The kinetics of imazapyr consumption was the first order with respect to imazapyr concentration and zero order with respect to ozone concentration with a constant rate of $0.247 \mathrm{~min}^{-1}$ and $0.128 \mathrm{~min}^{-1}$ for photocatalytic ozonation and heterogeneous photocatalysis, while the first order with respect to imazapyr and the first order with respect to ozone concentrations when only ozone was used with a constant rate of $0.053 \mathrm{~mol} \mathrm{~L}^{-1} \mathrm{~min}^{-1}$ at $\mathrm{pH}$. The degradation of imazapyr is strongly affected by operational parameters such as concentration of $\mathrm{TiO}_{2}$, concentration of ozone, primary concentration of imazapyr and $\mathrm{pH}$. The impact of $\mathrm{pH}$ on imazapyr degradation is affected mainly by the acid-base balance regulating the surface area of titanium oxides in water.

Under optimal conditions $\left(\mathrm{TiO}_{2}\right.$ dose of $100 \mathrm{mg} \mathrm{L}^{-1}$, ozone dose of $10 \mathrm{mg} \mathrm{L}^{-1}, 5 \mu \mathrm{M}$ of primary concentration of imazapyr and $\mathrm{pH} 7.00$ ), up to $90 \%$ of imazapyr removal was accomplished in $20 \mathrm{~min}$ with a removal constant rate of $0.247 \mathrm{~min}^{-1}$. Such high degradation efficiency for imazapyr herbicide is principally due to the development of further reactive and non-selective hydroxyl radicals in the oxidation medium and also the resulting synergistic effects between photocatalysis and ozone, which react more rapidly with imazapyr herbicide. The photogenerated electrons may interact with the ozone molecules producing ozonide radicals while reducing the potential occurrence of recombining electron hole pairs. On the basis of this study, the photocatalytic ozonation process can be recommended for practical application in wastewater treatment over other oxidative chemical processes.

Author Contributions: Conceptualization, S.B.; data curation, S.B., Z.B. and M.E.M.; investigation, S.B. and Z.B.; methodology, Z.B. and L.L.; project administration, F.J.H.F.; resources, L.L., M.E.M. and F.J.H.F.; supervision, F.J.H.F.; validation, F.J.H.F.; writing —original draft, S.B. All authors have read and agreed to the published version of the manuscript.

Funding: This research did not receive any external funding.

Acknowledgments: SB would like to acknowledge scholarship from CNRST Morocco.

Conflicts of Interest: The authors have no conflict of interest to declare. 


\section{References}

1. Crittenden, J.C.; Trussell, R.R.; Hand, D.W.; Howe, K.J.; Tchobanoglous, G. Water Treatment: Principles and Design, 3rd ed.; DFG form 53.01-05/16; Wiley: Hoboken, NJ, USA, 2012; pp. 8-11.

2. Tchobanoglous, G.; Stensel, H.D.; Tsuchihashi, R.; Burton, F.L. Wastewater Engineering: Treatment and Resource Recovery, 5th ed.; McGraw Hill: Singapore, 2014.

3. Richardson, S.D.; Ternes, T.A. Water Analysis: Emerging Contaminants and Current Issues. Anal. Chem. 2018, 90, 398-428. [CrossRef]

4. Loos, R.; Carvalho, R.; António, D.C.; Comero, S.; Locoro, G.; Tavazzi, S.; Paracchini, B.; Ghiani, M.; Lettieri, T.; Blaha, L.; et al. EU-wide monitoring survey on emerging polar organic contaminants in wastewater treatment plant effluents. Water Res. 2013, 47, 6475-6487. [CrossRef]

5. Kadi, M.W.; Ismail, A.A.; Mohamed, R.M.; Bahnemann, D.W. Photodegradation of the herbicide imazapyr over mesoporous $\mathrm{In}_{2} \mathrm{O}_{3}-\mathrm{TiO}_{2}$ nanocomposites with enhanced photonic efficiency. Sep. Purif. Technol. 2018, 205, 66-73. [CrossRef]

6. Bielan, Z.; Dudziak, S.; Sulowska, A.; Pelczarski, D.; Ryl, J.; Zielińska-Jurek, A. Preparation and Characterization of Defective $\mathrm{TiO}_{2}$. The Effect of the Reaction Environment on Titanium Vacancies Formation. Materials 2020, 13, 2763. [CrossRef]

7. Bougarrani, S.; El Azzouzi, L.; Akel, S.; Latrach, L.; Bouziani, A.; El Azzouzi, M. Factors Influencing Imazapyr Herbicide Removal from Wastewater Using Photocatalytic Ozonation. Acta Chim. Slov. 2018, 65, 470-474. [CrossRef]

8. Asano, T.; Burton, F.L.; Leverenz, H.L.; Tsuchihashi, R.; Tchobanoglous, G. Water Reuse: Issues, Technologies, and Applications; McGraw Hill: New York, NY, USA, 2007.

9. Atitar, M.F.; Dillert, R.; Bahnemann, D.W. Surface Interactions between Imazapyr and the $\mathrm{TiO}_{2}$ Surface: An in Situ ATR-FTIR. J. Phys. Chem. C 2017, 121, 4293-4303. [CrossRef]

10. Boggard, O.K.; Gimsing, A.L. Fate of glyphosate in soil and possibility of leading to ground and surface water-A review. Pest Manag. Sci. 2008, 64, 441-456. [CrossRef] [PubMed]

11. Fujishima, A.; Honda, K. Electrochemical Photolysis of Water at a Semiconductor Electrode. Nature 1972, 238, 37-38. [CrossRef] [PubMed]

12. Bamba, D.; Atheba, P.; Robert, D.; Trokourey, A.; Dongui, B. Photocatalytic degradation of the diuron pesticide. Environ. Chem. Lett. 2008, 6, 163-167. [CrossRef]

13. Langlais, B.; Reckhow, D.A.; Brink, D.R. Ozone in Water Treatment: Application and Engineering; Lewis Publishers: Boca Raton, FL, USA, 1991; pp. 3-8.

14. Lee, Y.; von Gunten, U. Oxidative transformation of micropollutants during municipal wastewater treatment: Comparison of kinetic aspects of selective (chlorine, chlorinedioxide, ferrate(VI), and ozone) and non-selective oxidants (hydroxyl radical). Water Res. 2010, 44, 555-566. [CrossRef] [PubMed]

15. Oller, I.; Gernjak, W.; Maldonado, M.I.; Pérez-Estrada, L.A.; Sanchez-Pérez, J.A.; Malato, S. Solar photocatalytic degradation of some hazardous water-soluble pesticides at pilot-plant scale. J. Hazard. Mater B 2006, 138, 507-517. [CrossRef] [PubMed]

16. Bougarrani, S.; Sharma, P.K.; Hamilton, J.W.; Singh, A.; Canle, M.; El Azzouzi, M.; Byrne, J.A. Enhanced Photocatalytic Degradation of the Imidazolinone Herbicide Imazapyr upon UV/Vis Irradiation in the Presence of Cax $\mathrm{MnO} y-\mathrm{TiO}_{2}$ Hetero-Nanostructures: Degradation Pathways and Reaction Intermediates. Nanomaterials (Basel) 2020, 10, 896. [CrossRef] [PubMed]

17. Ebrahimi, H.; Shahna, F.G.; Bahrami, A.; Jaleh, B.; Abedi, K.D. Photocatalytic degradation of volatile chlorinated organic compounds with ozone addition. Arch. Environ. Prot. 2017, 43, 165-172. [CrossRef]

18. Assalin, M.R.; De Moraes, S.G.; Queiroz, S.C.N.; Ferracini, V.L.; Duran, N. Studies on degradation of glyphosate by several oxidative chemical processes: Ozonation, photolysis and heterogeneous photocatalysis. J. Environ. Sci. Health B 2009, 45, 89-94. [CrossRef]

19. Kaichouh, G.; Oturan, N.; Oturan, A.M.; El Hourch, A.; El Kacemi, K. Mineralization of herbicides imazapyr and imazaquin in aqueous medium by, Fenton, photo-Fenton and électro-Fenton processes. Environ. Technol. 2008, 29, 489-496. [CrossRef]

20. Ikehata, K.; El-Din, M.G. Aqueous Pesticide Degradation by Ozonation and Ozone-Based Advanced Oxidation Processes: A Review (Part II). Ozone Sci. Eng. 2005, 27, 173-202. [CrossRef] 
21. Pizarro, P.; Guillard, C.; Perol, N.; Herrmann, J.M. Photo catalytic degradation of imazapyr in water: Comparison of activities of different supported and unsupported $\mathrm{TiO}_{2}$-based catalysts. Catal. Today 2005, 101, 211-218. [CrossRef]

22. Ismail, A.A.; Abdelfattah, I.; Faisal, M.; Helal, A. Efficient photodecomposition of herbicide imazapyr over mesoporous $\mathrm{Ga}_{2} \mathrm{O}_{3}-\mathrm{TiO}_{2}$ nanocomposites. J. Hazard. Mater. 2018, 342, 519-526. [CrossRef]

23. Shifu, C.; Yunzhang, L. Study on the photocatalytic degradation of glyphosate by $\mathrm{TiO}_{2}$ photocatalyst. Chemosphere 2007, 67, 1010-1017.

24. Maddila, S.; Rana, S.; Pagadala, R.; Jonnalagadda, S.B. Photocatalyzed ozonation: Effective degradation and mineralization of pesticide, chlorothalonil. Desalin. Water Treat 2015, 57, 14506-14517. [CrossRef]

25. Maddila, S.; Ndabankulu, V.O.; Jonnalagadda, S.B. Photocatalytic ozonation for the degradation of tetradifon pesticide on $\mathrm{Mn} / \mathrm{TiO}_{2}$ under visible light. Global NEST J. 2016, 18, 269-278.

26. Sanchez, L.; Peral, J.; Domenech, X. Aniline degradation by combined photocatalysis and ozonation. Appl. Catal. B 1998, 19, 59-65. [CrossRef]

27. Usharani, K.; Muthukumar, M.; Kadirvelu, K. Effect of $\mathrm{pH}$ on the Degradation of Aqueous Organophosphate (methylparathion) in Wastewater by Ozonation. Int. J. Environ. Res. 2012, 6, 557-564.

28. Gar Alalm, M.; Tawfik, A.; Ookawara, S. Comparison of solar $\mathrm{TiO}_{2}$ photocatalysis and solar photo-Fenton for treatment of pesticides industry wastewater: Operational conditions, kinetics, and costs. J. Water Proc. Eng. 2015, 8, 55-63. [CrossRef]

29. Bougarrani, S.; Skadell, K.; Arndt, R.; Azzouzi, M.; El Gläser, R. Novel Cax $\mathrm{MnO} y / \mathrm{TiO}_{2}$ composites for efficient photocatalytic degradation of methylene blue and the herbicide imazapyr in aqueous solution under visible light irradiation. J. Environ. Chem. Eng. 2018, 6, 1934-1942. [CrossRef]

30. Akpan, U.G.; Hameed, B.H. Parameters affecting the photocatalytic degradation of dyes using $\mathrm{TiO}_{2}$-based photocatalysts: A review. J. Hazard. Mater. 2009, 170, 520-529. [CrossRef]

31. Zhang, G.; Wang, Q.; Zhang, W.; Li, T.; Yuan, Y.; Wang, P. Effects of organic acids and initial solution pH 1 on photocatalytic degradation of bisphenol A (BPA) in a photo-Fenton-like process using Goethite $(\alpha-\mathrm{FeOOH})$. Photochem. Photobiol. Sci. 2016, 15, 1045-1053. [CrossRef]

32. Ismail, A.A.; Abdelfattah, I.; Atitar, M.F.; Robben, L.; Bouzid, H.; Al-Sayari, S.A.; Bahnemann, D.W. Photocatalytic degradation of imazapyr using mesoporous $\mathrm{Al}_{2} \mathrm{O}_{3}-\mathrm{TiO}_{2}$ nanocomposites. Sep. Purif. Technol. 2015, 145, 147-153. [CrossRef]

33. Atitar, M.F.; Ismail, A.A.; Dillert, R.; Bahnemann, D.W. Photodegradation of Herbicide Imazapyr and Phenol over Mesoporous Bicrystalline Phases $\mathrm{TiO}_{2}$ : A Kinetic Study. Catalysts 2019, 9, 640. [CrossRef]

Publisher's Note: MDPI stays neutral with regard to jurisdictional claims in published maps and institutional affiliations.

(C) 2020 by the authors. Licensee MDPI, Basel, Switzerland. This article is an open access article distributed under the terms and conditions of the Creative Commons Attribution (CC BY) license (http://creativecommons.org/licenses/by/4.0/). 